\title{
Treatment of chronic hepatic encephalopathy with levodopa ${ }^{1}$
}

\author{
MICHAEL LUNZER, I. M. JAMES, J. WEINMAN², AND SHEILA SHERLOCK \\ From the Departments of Medicine and Psychological Medicine, Royal Free Hospital, London
}

SUMMARY Three of six patients with chronic hepatic encephalopathy treated with levodopa showed a significant improvement. One patient was probably improved whilst the remaining two patients failed to show any benefit. Serial electroencephalography did not demonstrate significant changes. Treatment with levodopa was associated with an improvement in 'speed-based' tasks as assessed by computerized psychometry. A significant rise in cerebral oxygen consumption was found during levodopa therapy. Gastrointestinal side effects were dose limiting. It is concluded that a therapeutic trial of levodopa in patients with chronic hepatic encephalopathy is indicated when the response to conventional therapy has been poor.

Therapeutic measures for chronic hepatic encephalopathy have been directed towards either the direct removal of ammonia from the bowel or the elimination of substrates for ammonia production. Such measures include protein restriction (Summerskill, Davidson, Sherlock, and Steiner, 1956), antibiotics (Dawson, McLaren, and Sherlock, 1957), lactulose (Zeegan, Drinkwater, Fenton, Vince, and Dawson, 1970), and colonic exclusion or bypass (Walker, Emlyn-Williams, Craigie, Rosenoer, Agnew, and Sherlock, 1965).

Levodopa now has a well established place in the treatment of Parkinson's disease and other extrapyramidal disorders (Barbeau, 1969). Levodopa has also been shown to have an arousal effect on patients

${ }^{1}$ Presented in part to the British Society of Gastroenterology, London, September 1973.

'Present address: Unit of Psychology, Guy's Hospital Medical School, London, SE1.

Received for publication 28 March 1974. with acute hepatic coma (Parkes, Sharpstone, and Williams, 1970; Fischer and Baldessarini, 1971). Chronic hepatic encephalopathy, particularly if progressive and resistant to conventional therapy, commonly has both a cortical and extrapyramidal component. For these reasons we have carried out a therapeutic trial of levodopa in chronic hepatic encephalopathy. All patients had abnormal electroencephalograms, showed clinical evidence of severe neurological impairment, and had demonstrated a poor response to a low-protein diet, lactulose or neomycin, and, in two cases, colonic exclusion.

\section{Materials and Methods}

Six patients with cirrhosis and severe chronic hepatic encephalopathy were admitted to the trial. Clinical details of the patients are outlined in table I. The ages of the patients ranged from 41 to 70 years and all patients had cryptogenic cirrhosis confirmed by hepatic biopsy. In most patients the encephalopathy was longstanding, verying from one to 18 years.

\begin{tabular}{llllrl}
\hline Patient & Age & Sex & Diagnosis & Duration of Encephalopathy & Portal-systemic Shunt \\
\hline D.I. & 63 & M & F & Cryptogenic cirrhosis & 18 years \\
P.C. & 64 & M & Cryptogenic cirrhosis & 8 years & Natural \\
T.McC. & 47 & M & Cryptogenic cirrhosis & 11 years & Natural \\
H.B. & 61 & F & Cryptogenic cirrhosis & 6 years & Surgical \\
W.C. & 70 & M & Cryptogenic cirrhosis & 1 year & Natural \\
W.D. & 41 & Cryptogenic cirrhosis & 7 years & Surgical \\
\hline
\end{tabular}

Table I Patients receiving levodopa

${ }^{1}$ Colonic exclusion 
Three of the patients had had previous portacaval anastomoses whilst the remaining three had 'natural' portal-systemic shunts.

Patients were maintained on their previous therapy and introduced to levodopa in a dosage regime similar to the rapid introduction one described by Godwin-Austen, Frears, and Bergmann (1971). The incidence of side effects has not been found higher with such an introduction to treatment.

After 12 weeks' maintenance on levodopa the trial was continued on a double-blind crossover basis during which the patients were maintained on either levodopa or placebo (lactose) for two eightweek periods. Because of troublesome gastrointestinal side effects three patients had to be withdrawn eight, 11, and 12 weeks after commencing levodopa and only three patients remained in the second part of the trial (fig 1).

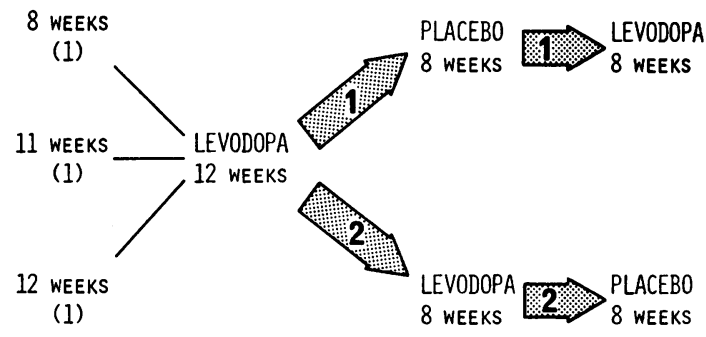

Fig 1 Design of levodopa trial

Patients were assessed (a) clinically by two independent physicians, (b) by serial electroencephalography, (c) by computerized psychometric testing, and (d) by measurements of cerebral metabolism and haemodynamics. Outpatient assessments were made at two- to four-week intervals and haematological, biochemical (renal and hepatic), and electrocardiographic changes were checked during therapy.

\section{ELECTROENCEPHALOGR APHY}

Electroencephalograms were performed before and during levodopa therapy using electrode placements in accordance with the 10-20 system with both conventional montages and more widely spaced electrodes being used. The activity from a single centro-occipital recording was also fed into a frequency analyser. The majority of patients had had repeated electroencephalograms for several years before receiving levodopa and showed persistent evidence of encephalopathy.

COMPUTERIZED PSYCHOMETRIC TESTING The computerized psychological test system is des- cribed in more detail elsewhere (Elithorn and Telford, 1969; Jones and Weinman, 1973). Test items are presented on a visual display and patients respond using selected teletype keys. The advantage of a system capable of generating large sets of parallel test items at varying levels of complexity is in its greater suitability for monitoring changes in motor and cognitive function in the individual patient than standard psychometric tests.

\section{Motor tapping}

This consists of tapping with the index finger the leftmost and rightmost keys on the bottom row of the computer teletype as quickly as possible. There were two separate runs for each hand and responses were timed and errors recorded.

\section{Auditory two-choice reaction time}

Here the patient is required to respond as quickly as possible with the right or left hand to a corresponding 'click' stimulus to the right or left ear.

\section{Ten-choice reaction time}

In this test the patient responds as quickly as possible to one of 10 equiprobable visual stimuli (digits 0 to 9) by pressing the corresponding teletype digit key.

\section{Digit-letter coding}

In this test the patient is presented with a 10 -item digit-letter code and responds to single letter stimuli by pressing the corresponding digit key. The task is presented under separate 'speed-stressed' and 'accuracy-stressed' conditions, as used by Heron and Chown (1967) in their study of aging.

\section{Digit span}

This provides an estimate of immediate memory span for visually presented digits at two separate rates of presentation: (a) one item every two seconds ('slow rate') and (b) one item every 0.4 seconds ('fast rate'). These two rates provide information about different aspects of short-term memory.

\section{Perceptual maze test}

This is a route-finding task requiring patients to find an optimal path through binary lattice-structured mazes (Jones and Weinman, 1973; Elithorn and Telford, 1969). The speed and accuracy of maze solving is particularly sensitive for organic impairment.

\section{CEREBRAL METABOLISM AND}

HAEMODYNAMICS

Cerebral blood flow was measured by the inhalation of radioactive ${ }^{133}$ xenon according to the method of Mallett and Veall (1965) in patients 1, 2, 3, 5, and 6. 
Corrections for arterial recirculation of the gas were made by monitoring the radioactivity of end tidal air. Subsequent deconvolutional analyses of the cerebral decay curve into three compartments were performed with an analogue computer (Crawley, 1968). The blood-brain partition coefficients for xenon used in the calculation of cerebral blood flow were those of Mallett and Veall (1965).

In patient 4 , cerebral blood flow was measured by the method of McHenry (1964), using ${ }^{85}$ Krypton.

In all patients arterial blood was obtained by puncture of the femoral artery and cerebral venous blood by jugular bulb puncture. Oxygen content was measured by the method of Linden, Ledsome, and Norman (1965) and glucose by a glucose oxidase method. $\mathrm{pH}, \mathrm{pCO}_{2}$ and $\mathrm{pO}_{2}$ were measured with the appropriate Radiometer electrodes.

\section{Results}

\section{CLINICAL RESPONSE (TABLE II)}

Before levodopa all patients showed intermittent or persistent drowsiness, variation of mood, and inversion of normal sleep rhythm. Speech was slurred and gait ataxic. Similarly all showed tremor, either resting or intention, and limb incoordination.

After levodopa in three patients gait improved and tremor lessened while coordination improved, to a lesser extent, in two patients. The beneficial effect was not restricted to extrapyramidal function. Three of the patients showed improvement in mood, became less drowsy, and reverted to a normal sleep rhythm. Speech was also markedly improved in two patients.

Three of the six patients showed definite clinical improvement. This was noted by the patients and their relatives and confirmed by clinical examination. A fourth patient was probably improved but the remaining two patients showed no change.

Only one of the improved patients was able to tolerate the drug sufficiently long for double-blind assessment. This patient showed a marked deterioration when changed to placebo and an improvement when recommenced on levodopa. The other two patients who were included in the double-blind assessment showed no difference between levodopa and placebo.

\section{ELECTROENCEPHALOGRAPHY}

Serial electroencephalograms were not significantly altered by levodopa. Initially all were mildly to moderately abnormal and, although the EEG became normal in two patients on levodopa, improvement was transient.

\begin{tabular}{lccccccc}
\hline Patient & Mental & Speech & Gait & Tremor & Incoordination & Overall Response \\
\hline D.I. & ++ & ++ & ++ & ++ & 0 & Dose (g/day) & Definite improvement \\
P.C. & 0 & 0 & 0 & + & + & Pro & Probable improvement \\
T.McC. & + & 0 & ++ & + & + & Definite improvement & $1 \cdot 5$ \\
H.B. & 0 & 0 & 0 & 0 & 0 & No response \\
W.C. & 0 & 0 & 0 & 0 & 0 & No response \\
W.D. & ++ & ++ & ++ & 0 & 0 & Definite improvement & $3 \cdot 5$ \\
\hline
\end{tabular}

Table II Clinical effect of levodopa on chronic hepatic encephalotpahy

++ definite improvement, + probable improvement, 0 no change

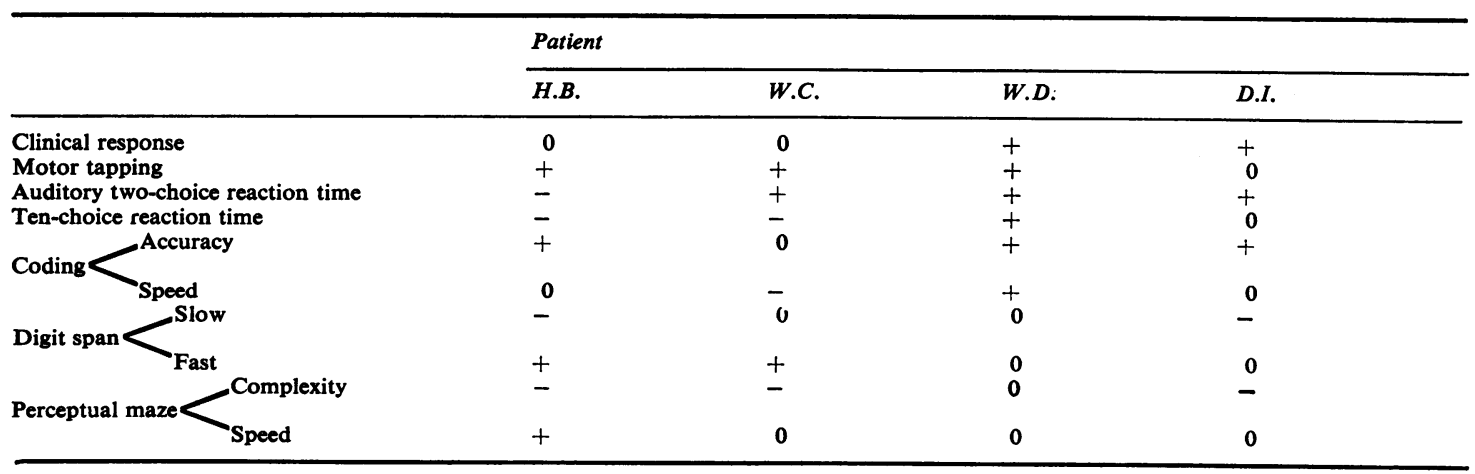

Table III Psychometric assessment of patients receiving levodopa

Improvement + , no change $\mathbf{0}$, deterioration - 


\begin{tabular}{|c|c|c|c|c|c|c|c|}
\hline \multirow[t]{2}{*}{ Patient } & \multirow[t]{2}{*}{ Clinical Response } & \multicolumn{2}{|c|}{$\begin{array}{l}\text { Cerebral Blood Flow } \\
(\mathrm{ml} / 100 \mathrm{~g} / \mathrm{min})\end{array}$} & \multicolumn{2}{|c|}{$\begin{array}{l}\text { Cerebral Oxygen Consumption } \\
(\mathrm{ml} / 100 \mathrm{~g} / \mathrm{min})\end{array}$} & \multicolumn{2}{|c|}{$\begin{array}{l}\text { Cerebral Glucose Consumption } \\
(\mathrm{ml} / 100 \mathrm{~g} / \mathrm{min})\end{array}$} \\
\hline & & Before & After (3 weeks) & Before & After & Before & After \\
\hline $\begin{array}{l}\text { D.I. } \\
\text { P.C. } \\
\text { T.McC. } \\
\text { H.B. } \\
\text { W.C. } \\
\text { W.D. }\end{array}$ & $\begin{array}{r}++ \\
+ \\
++ \\
0 \\
0 \\
++\end{array}$ & $\begin{array}{l}25 \\
27 \\
45 \\
32 \\
37 \\
26\end{array}$ & $\begin{array}{l}29 \\
26 \\
47 \\
46 \\
44 \\
26\end{array}$ & $\begin{array}{l}1 \cdot 3 \\
1.2 \\
2 \cdot 1 \\
2 \cdot 4 \\
1 \cdot 3 \\
1 \cdot 7\end{array}$ & $\begin{array}{l}1.9 \\
1.7 \\
2.1 \\
2.5 \\
1.6 \\
2.5\end{array}$ & $\begin{array}{l}1.8 \\
4 \cdot 0 \\
3 \cdot 9 \\
3 \cdot 2 \\
4 \cdot 8 \\
4 \cdot 2\end{array}$ & $\begin{array}{l}1.9 \\
1.6 \\
2.4 \\
3.2 \\
2.7 \\
6.0\end{array}$ \\
\hline $\begin{array}{l}\text { Mean } \\
\text { SEM }\end{array}$ & & $\begin{array}{l}32 \\
3 \cdot 2\end{array}$ & $\begin{array}{l}36 \\
4 \cdot 2\end{array}$ & $\begin{array}{l}1 \cdot 7 \\
0 \cdot 2\end{array}$ & $\begin{array}{l}2 \cdot 1^{1} \\
0 \cdot 2\end{array}$ & $\begin{array}{l}3 \cdot 7 \\
0 \cdot 4\end{array}$ & $\begin{array}{l}3.0 \\
0.6\end{array}$ \\
\hline
\end{tabular}

Table IV Effect of levodopa on cerebral metabolism and haemodynamics

${ }^{1}$ Significantly different from control value at $5 \%$ level (paired analysis)

++ Definite improvement, + probable improvement, 0 no change

\section{COMPUTERIZED PSYCHOMETRIC TESTING}

(TABLE III)

All tests were performed without the observer knowing whether drug or placebo was being given. Only four patients were seen often enough for a suitable on/off-dopa comparison to be made.

W.D. showed the most positive responses on levodopa and the other three patients showed a rather mixed response. However, consistent improvements were found on 'speed-based' tasks, ie, motor tapping, auditory reaction time, and coding. There was little change, however, on the higher level cognitive tasks except on some of the speed components of these tests.

CEREBRAL METABOLISM AND HAEMO-

DYNAMICS (TABLE IV)

In most patients there was an increase in cerebral oxygen consumption. Apart from T.McC. this correlated well with clinical improvement. The mean oxygen consumption increased from $1.7 \mathrm{ml} / 100$ $\mathrm{g} /$ minute to $2.1 \mathrm{ml} / 100 \mathrm{~g} /$ minute. This increase is significant at the $5 \%$ level by paired analysis (fig 2 ).

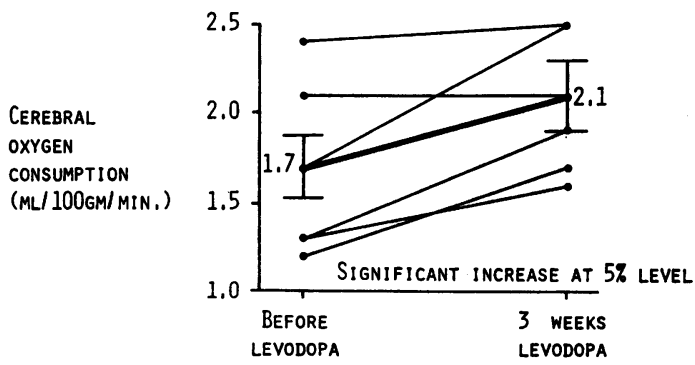

No SIGNIFICANT CHANGE IN CEREBRAL BLOOD FLOW OR CEREBRAL GLUCOSE CONSUMPTION

Fig 2 Effect of levodopa on cerebral metabolism in chronic hepatic encephalopathy.
Although there was no consistent change in cerebral glucose consumption, most patients showed an improvement in the oxygen-glucose index. If the index is calculated in the conventional way as

$$
\frac{\mathrm{A}-\mathrm{V} \mathrm{O}_{2}(\mathrm{~m} \text { mole }) \times 100}{6 \times \mathrm{A}-\mathrm{V} \text { glucose }(\mathrm{m} \text { mole })} \%
$$

then a mean value of $56 \%$ increased to a value of $93 \%$ as a result of therapy.

These changes in brain metabolism were not accompanied by significant changes in cerebral blood flow, arterial $\mathrm{pCO}_{2}$, or $\mathrm{pH}$.

\section{DOSAGE AND SIDE EFFECTS}

The mean daily dose of levodopa was $2 \cdot 1 \mathrm{~g}$ per day. These doses were lower than those commonly used in the treatment of Parkinson's disease. The reason for this is not clear but may be related to the role of the liver in the decarboxylation of levodopa.

The dose-limiting factor in all patients was gastrointestinal side effects (table V). All patients complained of nausea when their maintenance dose was exceeded. The only biochemical changes noted during levodopa therapy were small rises in serum levels of unconjugated bilirubin, uric acid, and aspar-

\begin{tabular}{|c|c|c|c|c|c|c|c|c|}
\hline \multicolumn{9}{|l|}{ Symptomatic } \\
\hline Nausea .. & . & .. & .. & . & .. & .. & .. & .. \\
\hline Anorexia & $\ldots$ & .. & .. & . & .. & .. & .. & .. \\
\hline Vomiting & .. & .. & .. & . & .. & .. & .. & .. \\
\hline Diarrhoea & .. & $\ldots$ & .. & . & .. & .. & $\ldots$ & $\ldots$ \\
\hline Palpitations & .. & .. & .. & . & .. & .. & .. & .. \\
\hline \multirow{2}{*}{\multicolumn{2}{|c|}{$\begin{array}{l}\text { Postural hypotension } \\
\text { Facial dyskinesia }\end{array}$}} & $\ldots$ & .. & . & .. & .. & .. & $\ldots$ \\
\hline & & .. & .. & . & .. & .. & .. & .. \\
\hline \multicolumn{9}{|l|}{ Biochemical } \\
\hline \multicolumn{6}{|c|}{ Transient unconjugated hyperbilirubinaemia } & . & . & .. \\
\hline \multirow{2}{*}{\multicolumn{4}{|c|}{$\begin{array}{l}\text { Transient hyperuricaemia } \\
\text { Transient increase in transaminase }\end{array}$}} & .. & .. & .. & . & .. \\
\hline & & & & .. & .. & . & .. & .. \\
\hline
\end{tabular}

Table V Toxicity of levodopa in six patients 
tate transaminase. In all cases these increases were transient despite continuation of therapy.

\section{Discussion}

A chronic neuropsychiatric syndrome is a well recognized complication of chronic liver disease (McDermott and Adams, 1954; Victor, Adams, and Cole, 1965; Read, Sherlock, Laidlaw, and Walker, 1967). This syndrome may present classically with intermittent drowsiness, confusion, and a flapping tremor. However, in other cases the presentation is less typical. Disorders of the cerebellum and extrapyramidal system are not uncommon and patients may present with a clinical picture very similar to that of Parkinson's disease. Less commonly, the corticospinal tract may be involved with hyperreflexia, extensor plantar responses, and hemiparesis (Williams and Toghill, 1968).

Chronic hepatic encephalopathy is a common complication of portal-systemic shunting operations (Read, Laidlaw, and Sherlock, 1961; Reynolds, Hudson, Mikkelsen, Turrill, and Redeker, 1966). The syndrome, however, may be observed in patients with chronic liver disease who have not been subjected to a surgical shunt and in this situation one usually finds clinical or radiological evidence of large portal-systemic venous collaterals in the abdomen, ie, a 'natural shunt'.

The response of chronic hepatic encephalopathy to conventional therapy is usually satisfactory. However, occasional patients fail to respond and show progressive neurological deterioration. Colonic exclusion or bypass has been advocated for such patients but the mortality rate of these operations is high and the benefit often transient and disappointing (Walker et al, 1965; Resnick, Ishihara, Chalmers, Schimmel, and the Boston Inter-Hospital Liver Group, 1968).

The successful use of levodopa in several extrapyramidal disorders and the reported arousal effect of this drugin acute hepatic coma suggested that levodopa might have a beneficial effect in resistant chronic hepatic encephalopathy. In this trial levodopa has been given to six patients with advanced neurological disease involving both cortical and extrapyramidal function. The small number of patients studied is a reflection of the rarity of this form of encephalopathy. Three of the six patients showed undoubted clinical improvement whilst a fourth probably benefited. In Parkinson's disease levodopa is effective mainly against rigidity and akinesia and, to a lesser extent, tremor. Our patients, however, also improved mentally and in speech.

Read, McCarthy, Ajdukiewicz, and Brown (1968) have emphasized the importance of the early diag- nosis and treatment of chronic hepatic encephalopathy and have suggested that there is an early (preclinical) stage during which cerebral pathology and dysfunction are potentially reversible. All of the patients in this trial had advanced neurological disease with probable irreversible histological changes in the brain. Levodopa might have a more strikingly beneficial effect if given earlier. A trial of the effect of levodopa in the prevention of encephalopathy immediately after portal-systemic shunt surgery would be interesting.

The failure of serial electroencephalograms to show any significant improvement was disappointing but, again, could be explained by there being an irreversible component in the encephalopathy. Others have claimed dramatic electroencephalographic improvement after levodopa in patients with both acute (Parkes et al, 1970) and acute-on-chronic (Fischer and Baldessarini, 1971) hepatic encephalopathy. Since the completion of this trial we have observed a patient receiving levodopa who showed both a clinical improvement and a return to a normal EEG pattern for the first time in five years.

Computerized psychometric assessment suggests that the primary effect of levodopa is speeding certain responses, particularly those involving controlled hand movements and decision speed to simple choice stimuli. From other studies we have performed on cirrhotic patients the greatest impairment in the patients with chronic hepatic encephalopathy seems to be on these same 'speed-based' tasks. A similar response pattern to levodopa has been found in Parkinsonian patients (Jones and Weinman, 1973).

Patients with chronic hepatic encephalopathy nearly always have a low cerebral oxygen consumption and evidence of anaerobic glycolysis. Clinical improvement is associated with an increase in oxygen utilization (Fazekas, Ticktin, and Ehrmantraut 1956; Posner and Plum, 1960; Polli, Bianchi Porro, and Maiolo, 1969). Previous studies from this department have shown similar pretreatment values in patients with hepatic encephalopathy with increases in oxygen consumption following the beneficial action of lactulose (James and Garassini, 1971). Levodopa over a period of three weeks did result in a significant increase in brain oxygen consumption and an improvement in the oxygen-glucose index. Although there have been no previous studies on the effect of levodopa on cerebral metabolism in man, the acute intravenous infusion of levodopa in the dog in appropriate comparable doses results in an increase in both oxygen and glucose consumption of the brain (unpublished observation). It is characteristic of catecholamines that, although causing an increase in cerebral oxygen consumption, they also induce anaerobic glycolysis (Xanalatos and James, 
1972; MacDonell, Xanalatos, Hall, and James, 1972). However, no evidence of increasing systemic lactic acidosis was seen in our patients and, as already mentioned, the oxygen-glucose ratio improved. It is also unlikely that systemic anaerobic glycolysis was provoked by levodopa in these patients as there was no appreciable change in systemic acidbase status as judged by arterial $\mathrm{pH}$ and $\mathrm{pCO}_{2}$.

The mechanism of the beneficial action of levodopa in chronic hepatic encephalopathy is speculative. Patients with Parkinson's disease usually have diminished amounts of dopamine in the extrapyramidal nuclei and, as dopamine is the dominant extrapyramidal neurotransmitter, the action of levodopa in this disease may depend on the replenishment of depleted dopamine in these nuclei. However, our patients showed evidence of improved cortical and cerebellar, as well as extrapyramidal, function. It would appear, therefore, that abnormalities of neurotransmitter metabolism are more widespread in hepatic encephalopathy than in Parkinson's disease. Fischer and Baldessarini (1971) have suggested that both encephalopathy and other non-cerebral manifestations of hepatic failure might be due to abnormal neurotransmission. They postulate that amines with a close structural relationship to the physiological neurotransmitters, dopamine and noradrenaline, act as 'false neurotransmitters' in liver disease by replacing the physiological neurotransmitters with a consequent diminution in response of the effector organ, whether it be brain, kidney, heart, or the peripheral circulation. Recent work from this department has confirmed a defect in autonomic control of the peripheral circulation in liver disease (Lunzer, Newman, and Sherlock, 1973; Lunzer, Manghani, Newman, and Sherlock, 1973). An analogy might be drawn with Parkinson's disease in which both a central extrapyramidal disturbance responsive to levodopa and peripheral autonomic dysfunction have been found (Appenzeller and Goss, 1971).

The results of this study suggest that levodopa may provide a safe and more effective method of treatment of intractable chronic hepatic encephalopathy.

\section{M.L. is Watson Smith fellow of the Royal College of Physicians.}

We thank Dr Oliver James for his invaluable help with the clinical assessment. We also thank Dr Jean Kennedy of the Electroencephalography Department and Dr Alick Elithorn and Miss Judith James of the Department of Psychological Medicine for their help and facilities during this study.

Levodopa and placebo were kindly supplied by Dr A. N. Duffus of Roche Pharmaceuticals Ltd.

\section{References}

Appenzeller, O., and Goss, J. E. (1971). Autonomic deficits in Parkinson's syndrome. Arch. Neurol., 24, 50-57.

Barbeau, A. (1969). L-Dopa therapy in Parkinson's disease. Canad. med. Ass. J., 101, 791-800.

Crawley, J. C. W. (1968). An analogue computer for calculating blood perfusion rates. Bio-med. Engng, 3, 256-261.

Dawson, A. M., McLaren, J., and Sherlock, S. (1957). Neomycin in the treatment of hepatic coma. Lancet, 2, 1263-1268.

Elithorn, A., and Telford, A. (1969). Computer analysis of intellectual skills. Int. J. Man-Mach. Stud., 1, 189-209.

Fazekas, J. F., Ticktin, H. E., Ehrmantraut, W. R., and Alman, R. W. (1956). Cerebral metabolism in hepatic insufficiency. Amer. J. Med., 21, 843-849.

Fischer, J. E., and Baldessarini, R. J. (1971). False neurotransmitters and hepatic failure. Lancet, 2, 75-79.

Godwin-Austen, R. B., Frears, C. C., and Bergmann, S. (1971). Incidence of side effects from levodopa during the introduction of treatment. Brit. med. J., 1, 267-268.

Heron, A., and Chown, S. (1967). Age and Function. Churchill, London.

James, I. M., and Garassini, M. (1971). Effect of lactulose on cerebral metabolism in patients with chronic portosystemic encephalopathy. Gut, 12, 702-704.

Jones, D., and Weinman, J. (1973). Computer based psychological testing. In Human and Artificial Intelligence, pp. 83-93. Elsevier, Amsterdam.

Linden, R. J., Ledsome, J. R., and Norman, J. (1965). Simple methods for the determination of the concentrations of carbon dioxide and oxygen in blood. Brit. J. Anaesth., 37, 77-88.

Lunzer, M., Manghani, K., Newman, S. P., and Sherlock, S. (1973). The autonomic neuropathy of liver disease. Gut, 14, 820 .

Lunzer, M., Newman, S. P., and Sherlock, S. (1973). Skeletal muscle blood flow and neurovascular reactivity in liver disease. Gut, 14, 354-359.

McDermott, W. V.,Jr.,and Adams, R. D. (1954). Episodic stupor associated with an Eck fistula in the human with particular reference to the metabolism of ammonia. J. clin. Invest., 33, 1-9.

MacDonell, L., Xanalatos, C., Hall, S., and James, I. M. (1972). Factors affecting the response of cerebral metabolism and blood flow to a noradrenaline infusion in the dog. Europ. Neurol., 6, 208-212.

McHenry, L. C. (1964). Quantitative cerebral blood flow determination. Neurology (Minneap.), 14, 785-793.

Mallett, B. L., and Veall, N. (1965). The measurement of regional cerebral clearance rates in man using Xenon-133 inhalation and extracranial recording. Clin. Sci., 29, 179-191.

Parkes, J. D., Sharpstone, P., and Williams, R. (1970). Levodopa in hepatic coma. Lancet, 2, 1341-1343.

Polli, E., Bianchi Porro, G., and Maiolo, A. T. (1969). Cerebral metabolism after portacaval shunt. Lancet, 1, 153.

Posner, J. B., and Plum, F. (1960). The toxic effects of carbon dioxide and acetazolamide in hepatic encephalopathy. J. clin. Invest., 39, 1246-1258.

Read, A. E., Laidlaw, J., and Sherlock, S. (1961). Neuropsychiatric complications of portacaval anastomosis. Lancet, 1, 961-963.

Read, A. E., McCarthy, C. F., Ajdukiewicz, A. B., and Brown, G. J. A. (1968). Encephalopathy after portacaval anastomosis. Lancet, 2, 999-1001.

Read, A. E., Sherlock, S., Laidlaw, J., and Walker, J. G. (1967). The neuropsychiatric syndromes associated with chronic liver disease and an extensive portal-systemic collateral circulation. Quart. J. Med., 36, 135-150.

Resnick, R. H., Ishihara, A., Chalmers, T. C., Schimmel, E. M., and the Boston Inter-Hospital Liver Group (1968). A controlled trial of colon bypass in chronic hepatic encephalopathy. Gastroenterology, 54, 1057-1069.

Reynolds, T. B., Hudson, N. M., Mikkelsen, W. P., Turrill, F. L., and Redeker, A. G. (1966). Clinical comparison of end-to-side and side-to-side portacaval shunt. New Engl. J. Med., 274, 706-710.

Summerskill, W. H. J., Davidson, E. A., Sherlock, S., and Steiner, R. E. (1956). The neuropsychiatric syndrome associated with hepatic cirrhosis and an extensive portal collateral circulation. Quart. J. Med., 25, 245-266.

Victor, M., Adams, R. D., and Cole, M. (1965). The acquired (nonWilsonian) type of chronic hepato-cerebral degeneration. Medicine (Baltimore), 44, 345-396.

Walker, J. G., Emlyn-Williams, A., Craigie, A., Rosenoer, V. M., Agnew, J., and Sherlock, S. (1965). Treatment of chronic 
portal-systemic encephalopathy by surgical exclusion of the colon. Lancet, 2, 861-866.

Williams, R., and Toghill, P. J. (1968). The widening spectrum of neurological damage in liver disease. Postgrad. med. J., 44, 173-177.

Xanalatos, C., and James, I. M. (1972). Effect of arterial $\mathrm{CO}_{2}$ pressure

on the response of cerebral and hind-limb blood flow and metabolism to isoprenaline infusion in the dog. Clin. Sci., 42 , 63-68.

Zeegen, R., Drinkwater, J. E., Fenton, J. C. B., Vince, A., and Dawson, A. M. (1970). Some observations on the effects of treatment with lactulose on patients with chronic hepatic encephalopathy. Quart. J. Med., 39, 245-263. 